\title{
EFEITO DA IMPLEMENTAÇÃO DE FEEDBACKS SEMANAIS SOBRE RELATÓRIOS DE PRÁTICAS DE LABORATÓRIO DE MATERIAIS DE CONSTRUÇÃO CIVIL
}

\author{
Alexandre Conrado Maia Vidal-alexandreconrado@alu.ufc.br \\ Universidade Federal do Ceará, Departamento de Engenharia Estrutural e Construção Civil \\ Campus Universitário do Pici, Bloco 733 - Pici. \\ 60455-760 - Fortaleza - Ceará
}

Tallys Gonçalves Pereira-tallyspereira@alu.ufc.br

Universidade Federal do Ceará, Departamento de Engenharia Estrutural e Construção Civil Campus Universitário do Pici, Bloco 733 - Pici.

60455-760 - Fortaleza - Ceará

Lucas Feitosa de Albuquerque Lima Babadopulos - babadopulos@ufc.br

Universidade Federal do Ceará, Departamento de Engenharia Estrutural e Construção Civil Campus Universitário do Pici, Bloco 733 - Pici.

60455-760 - Fortaleza - Ceará

\begin{abstract}
Resumo: As disciplinas de materiais de construção civil, do terceiro e do quarto semestres do curso de engenharia civil, são as primeiras oportunidades de contato específico dos estudantes com temas que farão parte da sua vivência profissional. Por meio de aulas práticas em laboratório, os alunos aprendem acerca do funcionamento dos ensaios de caracterização de materiais e de seu controle tecnológico, elaborando relatórios técnicos para cada aula. Em decorrência de erros recorrentes dos alunos nos textos, foi implantada uma rotina de feedbacks semanais sobre os relatórios, assim como um modelo padronizado de relatório simplificado de aula prática. O objetivo deste artigo é avaliar os benefícios dessas duas ações, executadas pela equipe de monitoria da disciplina. Para avaliar a eficácia das medidas tomadas, utilizou-se uma análise estatística para comparar as notas anteriores e posteriores às mudanças. Foi observado aumento de nota média em todos os quartis analisados. Observou-se um aumento maior no desempenho dos estudantes que possuíam notas menores (especialmente o $4^{o}$ quartil) anteriormente à aplicação do feedback, sendo essa evolução de aproximadamente $18 \%$ na nota média dos relatórios. A estratégia equilibrou o desempenho dos alunos, que antes da implantação possuíam notas mais dispersas, com coeficiente de variação de 11,8\%, reduzindo para 5,4\% ao final do semestre. Por fim, foi constatado que $82 \%$ da turma teve seu desempenho melhorado após a implantação do sistema de feedbacks, confirmando a eficácia do método para a situação aqui analisada.
\end{abstract}

Palavras-chave: Engenharia Civil. Feedback semanal. Relatórios técnicos. Padronização. 


\section{INTRODUÇÃO}

Em geral, durante o primeiro ano dos cursos de engenharia, as referências à vivência profissional no conteúdo das disciplinas básicas são escassas. As disciplinas dos semestres iniciais configuram o chamado Ciclo Básico, período no qual os alunos são submetidos a formações teóricas em matérias fundamentais para futura aplicação na solução de problemas de engenharia. De acordo com Santos (1998), problemas como desmotivação, inflexibilidade das disciplinas e dificuldade de adaptação com a organização curricular universitária podem favorecer o fenômeno da evasão acadêmica durante o ciclo básico dos cursos de engenharia.

Almeida (2017) apontou as causas de ordem pedagógica como as principais responsáveis pelo problema de evasão nas escolas de engenharia. O estudo observou que as origens do problema estão predominantemente atreladas à ocorrência de reprovações sucessivas, deficiências na formação básica e metodologias didático-pedagógicas pouco eficazes.

Em vista disso, a presente pesquisa buscou avaliar a implementação de estratégias simples de feedback, para fazer face a um problema vivenciado no curso de Engenharia Civil da Universidade Federal do Ceará: o desempenho deficiente dos alunos na elaboração de relatórios de práticas de laboratório. As disciplinas de Materiais de Construção Civil I e II constituem as primeiras oportunidades de contato dos estudantes com assuntos que, de fato, farão parte diretamente de sua atividade profissional, qualquer que seja a área de ênfase escolhida em seguida. Por meio de aulas de laboratório, os alunos aprendem acerca do funcionamento e da utilidade dos ensaios de caracterização e de controle tecnológico dos materiais. Posteriormente, é solicitado que os alunos elaborem relatórios técnicos que sintetizem o conteúdo de forma prática, em uma tentativa de aproximação com a concepção de laudos técnicos. Contudo, a inexperiência dos estudantes na preparação desse tipo de texto, aliada à concorrência com as demais atividades do semestre, colaboram para desempenhos insatisfatórios, refletidos regularmente nas notas dos relatórios, algo que costuma perdurar ao longo do semestre, em que são exigidos cerca de 10 relatórios ( 1 por semana, com exceção da $1^{\mathrm{a}}$ semana do semestre, das semanas de provas e de eventuais feriados).

$\mathrm{O}$ ato de fornecer feedback pode ser entendido como o conjunto de estratégias de retorno, na forma de informação, a partir da descrição e/ou da discussão do desempenho do aluno em alguma atividade específica (Zeferino et al., 2007). Para Filatro (2008), o feedback deve funcionar de maneira constante e contínua durante o processo de aprendizagem, evitando ocorrências exclusivas durante períodos de provas e testes. Segundo Hannah e Dettmer (2004), o uso de feedback em estratégias educacionais tem sua relevância atribuída à possibilidade de evolução simultânea de discentes e docentes, mediante o acúmulo de vivências. Macfarlane (2009) vai além e defende a existência de uma estreita relação entre o sucesso profissional do professor e sua capacidade de utilizar feedbacks, provenientes da percepção dos alunos, na autoavaliação da eficácia do seu ensino.

Nesta pesquisa, implementou-se um modelo de relatórios padronizado e simplificado, associado a um feedback emitido semanalmente aos alunos. Ambas estratégias foram construídas pelos bolsistas de iniciação à docência (monitores) da disciplina sob orientação do professor. A ideia principal era promover aos alunos da disciplina a chance de aprendizado a partir da prática e consequentemente dos erros cometidos, para além da aferição de notas comum ao ambiente acadêmico. O objetivo deste artigo é avaliar os benefícios das implementações do modelo padronizado de relatório simplificado e dos feedbacks semanais. 


\section{MÉTODOS}

A pesquisa aqui relatada foi realizada com os alunos da disciplina de Materiais de Construção Civil II no semestre 2019.2 mediante análise das notas atribuídas aos nove relatórios aplicados ao longo da disciplina. A turma possuía 40 alunos e os relatórios eram construídos em duplas, totalizando 20 relatórios a serem corrigidos semanalmente. Isso totalizou 159 relatórios (alguns alunos deixam de entregar alguns relatórios) incluídos na análise desta pesquisa. No Quadro 1, são apresentados os temas das aulas práticas, ilustrando o início da aplicação da estratégia de feedbacks com base no modelo de relatório simplificado proposto, a partir do quarto relatório exigido na disciplina.

Quadro 1-Sequência de temas dos relatórios com indicação da aplicação de feedbacks.
\begin{tabular}{|c|c|c|c|c|c|c|c|c|}
\hline \multicolumn{3}{|c|}{ Sem Feedback } & \multicolumn{7}{|c|}{ Com Feedback } \\
\hline Relatório 01 & Relatório 02 & Relatório 03 & Relatório 04 & Relatório 05 & Relatório 06 & Relatório 07 & Relatório 08 & Relatório 09 \\
\hline $\begin{array}{c}\text { Características } \\
\text { Geométricas de } \\
\text { Blocos Cerâmicos }\end{array}$ & $\begin{array}{c}\text { Resistência de } \\
\text { Blocos } \\
\text { Cerâmicos }\end{array}$ & $\begin{array}{c}\text { Propriedades da } \\
\text { Madeira }\end{array}$ & $\begin{array}{c}\text { Propriedades } \\
\text { do Aço }\end{array}$ & $\begin{array}{c}\text { Aditivos para } \\
\text { Concretos }\end{array}$ & $\begin{array}{c}\text { Concreto com } \\
\text { Fibras }\end{array}$ & $\begin{array}{c}\text { Agregados } \\
\text { para } \\
\text { Pavimentação }\end{array}$ & $\begin{array}{c}\text { Ligantes } \\
\text { Asfálticos }\end{array}$ & $\begin{array}{c}\text { Dosagem de } \\
\text { Misturas } \\
\text { Asfálticas }\end{array}$ \\
\hline
\end{tabular}

Fonte: Os próprios autores.

\subsection{Padronização dos relatórios}

Inicialmente, os relatórios eram produzidos a partir de um modelo com simples indicação da divisão das seções e do limite de tamanho (máximo de 2 páginas). Contudo, apesar de nortear a elaboração do texto, esse modelo abria margem para a ocorrência de erros de organização (textos que deveriam aparecer em uma seção apareciam em outra) e de formato (alteração de margens, tamanho de letra, etc., para atender ao limite de páginas sem esforço de concisão), dificultando a correção. Desse modo, a primeira estratégia adotada foi reformular o modelo de relatório, apresentando os tópicos exigidos e as respectivas orientações para o preenchimento de cada parte do texto (sem exceder o limite de 2 páginas e atendendo ao formato do template), como ilustrado no Quadro 2.

Quadro 2 - Estrutura padronizada do relatório com orientações.

\begin{tabular}{|l|l|l|}
\hline \multirow{2}{*}{$\begin{array}{l}\text { UFC } \\
\text { Nome: }\end{array}$} & \multicolumn{2}{|l|}{ Universidade Federal do Ceará } \\
\cline { 2 - 3 } & Departamento de Engenharia Estrutural e Construção Civil \\
\hline Nome: & Matrícula: \\
\hline Professor: & Matrícula: \\
\hline Prática: & Turma: \\
\hline \multicolumn{2}{|c|}{ Introdução } \\
\hline $\begin{array}{l}\text { O que colocar nesse tópico? } \\
\text { Tema da prática; } \\
\text { Pra que serve; } \\
\text { Porque é feito; } \\
\text { Qual a importância. }\end{array}$ \\
\hline
\end{tabular}


Quadro 2 - Estrutura padronizada do relatório com orientações (continuação).

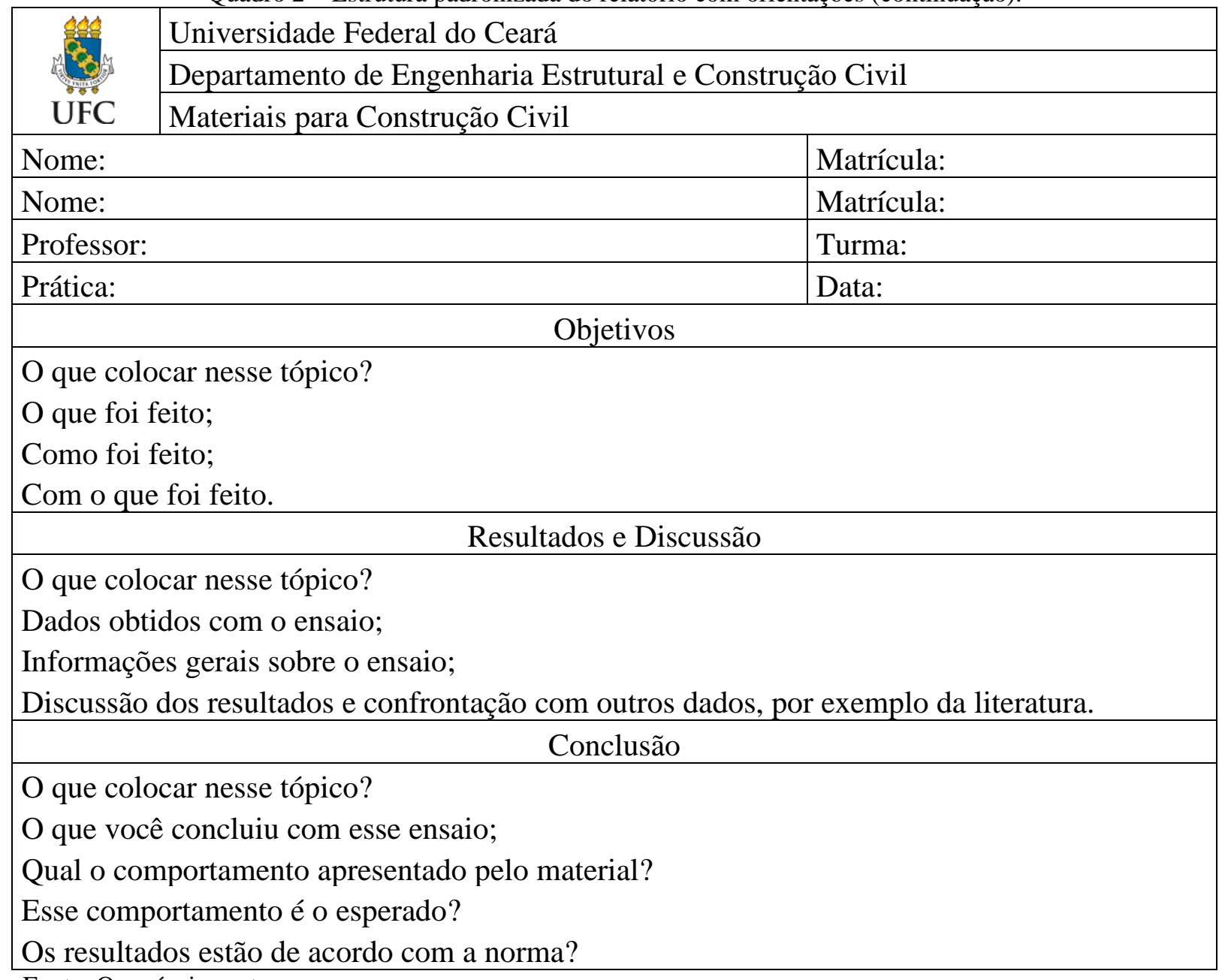

Fonte: Os próprios autores.

\subsection{Aplicação dos feedbacks}

$\mathrm{Na}$ presente pesquisa, a formulação das estratégias de feedback se deu por meio de dois tipos de feedback, um geral e outro individualizado. A aplicação era feita por escrito por meio de um documento anexado aos relatórios de cada dupla, com comentários personalizados, e através da elaboração de um feedback geral disponibilizado para toda a turma na plataforma de ensino. O feedback geral reunia a lista dos erros e aspectos positivos mais comuns, a serem discutidos também nas aulas práticas com o professor. A ideia era por um lado permitir a melhora individual de cada aluno, e por outro situá-lo em relação à turma e facilitar uma evolução de todo o grupo. Desse modo, os alunos tiveram a oportunidade de melhorar seus próximos trabalhos em pontos específicos e aprender também com os erros cometidos por outras duplas. Conforme apresentado no Quadro 1, foram aplicados os três relatórios iniciais com notas atribuídas de acordo com o formato tradicional, sem feedback, e partir do $4^{\circ}$ relatório, aplicou-se a sequência ilustrada na Figura 1. 
Figura 1 - Fluxograma de aplicação dos feedbacks.

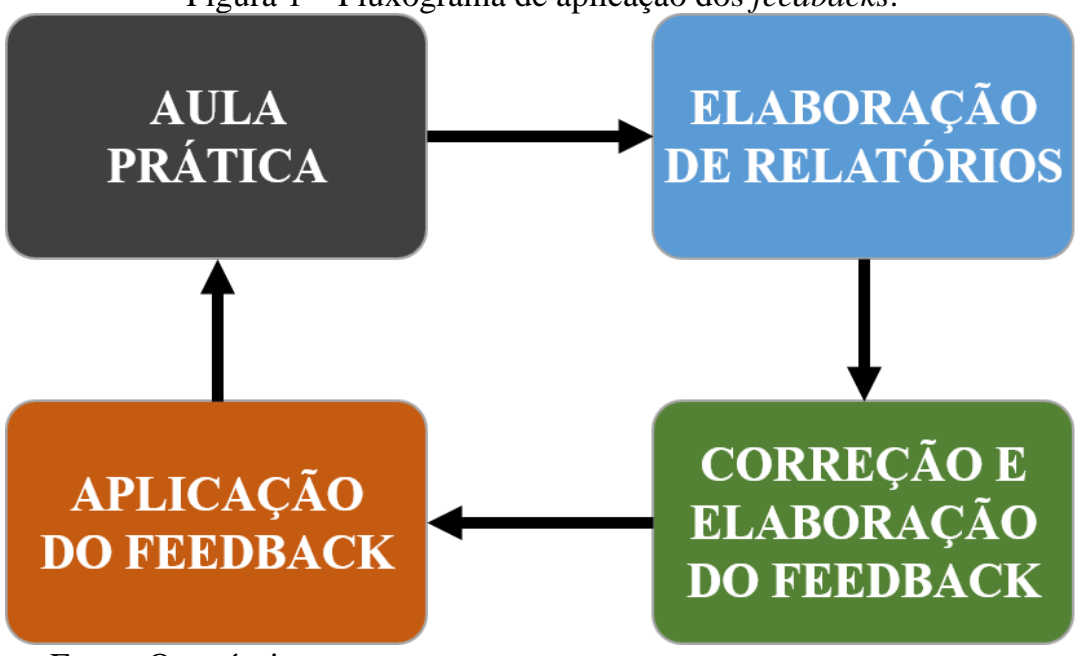

Fonte: Os próprios autores.

\section{RESULTADOS}

Nos três primeiros relatórios, antes da padronização dos relatórios e aplicação dos feedbacks, eram comuns erros de formatação, identificação dos autores e principalmente organização inadequada das informações nas seções, o que dificultava a correção padronizada dos relatórios. Informações de Conclusão e Metodologia, por exemplo, eram frequentemente alocadas na seção de Resultados, ao passo que os objetivos dos ensaios eram inseridos dentro da Introdução. Na seção de Conclusões, o erro mais comum era focar no aprendizado obtido (por exemplo com conclusões enfatizando a importância da própria aula ou da elaboração do relatório), em vez de focar no que os resultados experimentais demonstraram e o que se pode concluir a partir deles, como em um laudo técnico.

No tocante ao conteúdo apresentado pelos alunos, foi observada uma certa variedade de desempenhos. Algumas duplas apresentaram informações adicionais, como descrições sucintas de ensaios complementares que não puderam ser realizados no laboratório, mas que foram comentados durante as aulas, sem fugir do tema principal do ensaio. Por outro lado, houve casos em que os alunos foram superficiais nas informações apresentadas, demonstrando entendimento insuficiente do ensaio, ao apresentar análises incorretas e/ou incompletas dos resultados obtidos.

Ao final do semestre foram analisadas as notas dos 9 relatórios para as 20 duplas, com o intuito de se medir os avanços nas notas ao longo do semestre, particularmente antes e depois da implementação das estratégias de padronização e feedback. As duplas foram divididas em quartis de notas médias obtidas nos três primeiros relatórios, e os resultados obtidos tanto para eles como para a média dos seis demais relatórios são apresentados no Gráfico 1. 


\section{COBENGE C. COBENCE 2020 da ABENGE}

\section{"Os desafios para formar hoje o engenheiro do amanhã"}

Gráfico 1 - Notas médias antes e depois da implementação das estratégias, separadas por quartis das notas médias dos 3 primeiros relatórios.

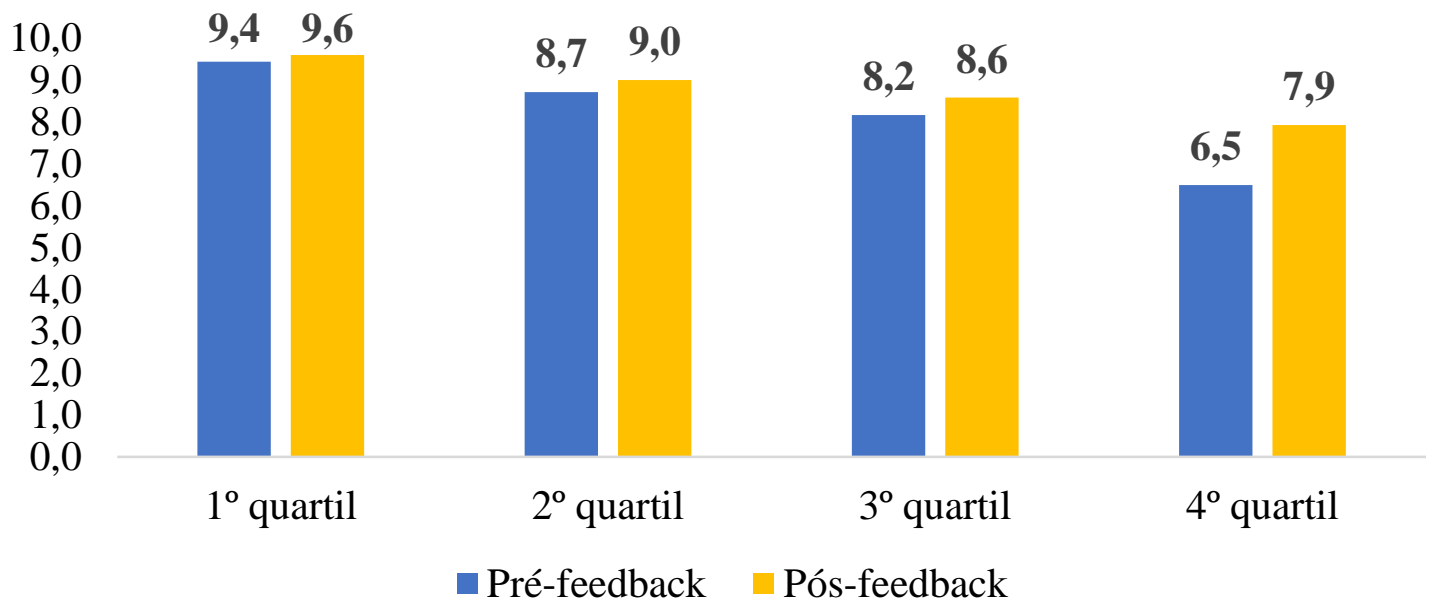

Fonte: Os próprios autores.

Com base no Gráfico 1, é possível perceber que nos quartis nos quais os alunos já apresentavam notas médias acima de 8,0 antes da implementação da estratégia, os avanços, ainda que sistemáticos, ocorreram em menor magnitude, aumentando no máximo 0,4 ponto na média dos relatórios, configurando uma evolução inferior a 5\%. Entretanto, no outro extremo, referente à faixa de alunos com nota média abaixo de 7,0 nos três primeiros relatórios, observou-se um notável avanço de 1,4 pontos na média, um aumento de quase $18 \%$ em relação ao início do semestre.

No Gráfico 2, é apresentada a evolução das médias de cada quartil em relação aos relatórios. Nota-se a já comentada pequena variação do primeiro quartil, oscilando dentro do intervalo de notas 9,0 e 10,0, e seu padrão de notas constantes próximas de 10,0 ao final do semestre. Esses alunos provavelmente já possuíam maior treinamento nesse tipo de atividade.

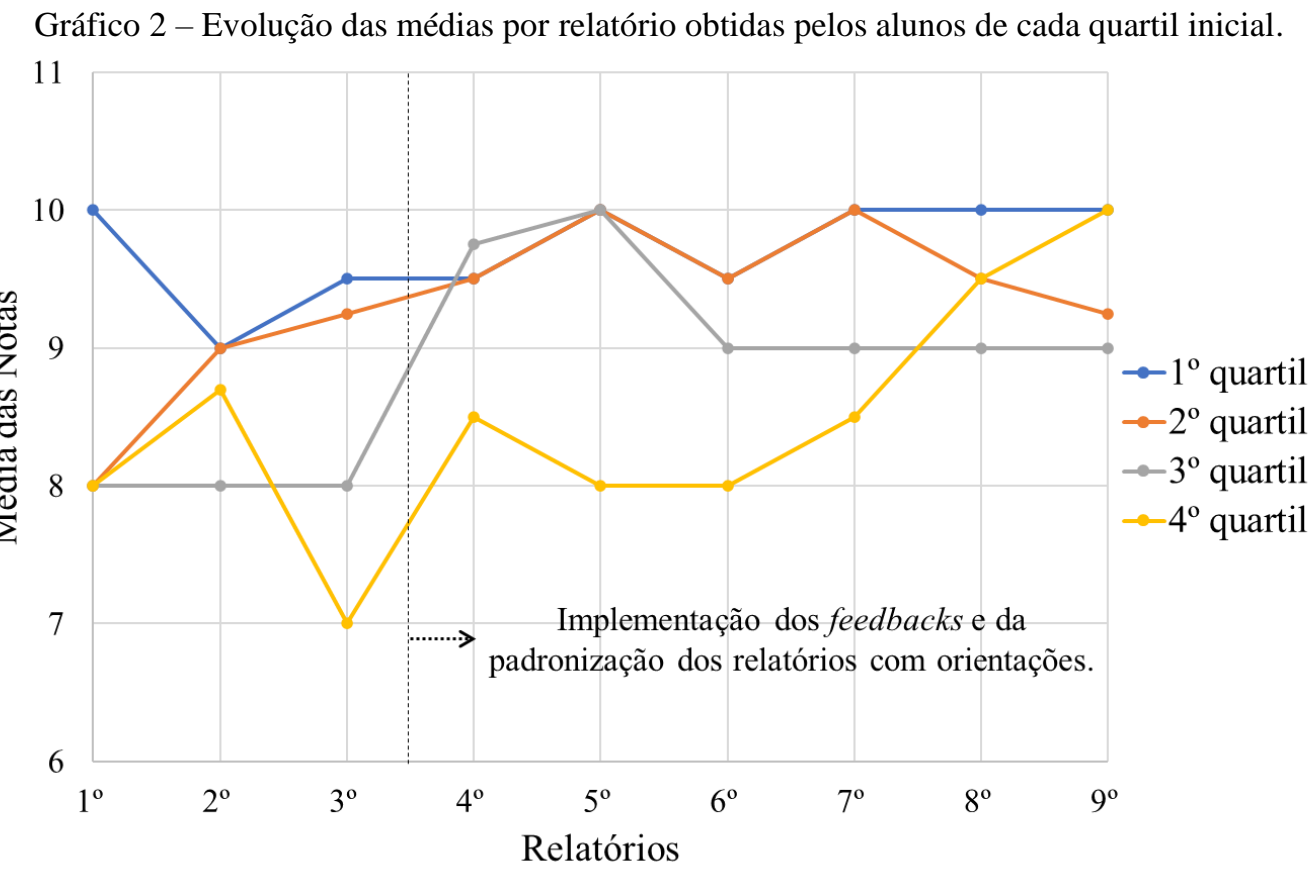

Fonte: Os próprios autores. 
O segundo quartil apresentou um aumento gradual até o $5^{\circ}$ relatório, quando também passaram a oscilar entre 9,0 e 10,0 em comportamento próximo ao do primeiro quartil inicial. É importante notar que, no caso dos alunos do segundo quartil, o incremento de notas foi observado mesmo antes da implementação das estratégias. São provavelmente alunos que conseguem o desempenho esperado mesmo sem intervenções mais incisivas por parte da equipe de docência.

O terceiro quartil experimentou o maior avanço entre duas entregas consecutivas, subindo mais de 1,5 pontos na média a partir da implementação dos feedbacks, no $4^{\circ}$ relatório. O bom desempenho se manteve após isso. Esses alunos responderam rapidamente e muito bem à implementação das estratégias. Por fim, o quarto quartil demonstrou a menor média no último relatório antes dos feedbacks, tendo como marco de ascensão a $5^{a}$ entrega, seguindo sua evolução até atingir o mesmo patamar de notas dos alunos do primeiro quartil inicial, no último relatório do semestre. Esses alunos foram mais reticentes em se envolver com maior intensidade com essa atividade e demoraram mais a responder às estratégias implementadas, ainda que tenham atingido o mesmo nível que os demais ao fim do semestre quanto à elaboração dos relatórios. Observa-se ainda que esse aumento significativo de notas ao fim do semestre também pode ser motivado pela aproximação do período de provas finais e a consequente necessidade de recuperação de notas dos alunos pertencentes ao $4^{\circ}$ quartil, dado seus baixos desempenhos nas primeiras entregas.

Para avaliar o grau de dispersão das notas médias dos relatórios de toda a turma a cada entrega, foi calculado o coeficiente de variação (CV) para os quatro quartis, estando o resultado apresentado no Gráfico 3. A partir dos valores obtidos, é possível destacar que, anteriormente à aplicação dos feedbacks, a dispersão das notas médias atingiu valores máximos, de $11,8 \% \mathrm{e}$ $13,8 \%$, no $1^{\circ}$ e $3^{\circ}$ relatórios, respectivamente. Nota-se uma redução para $6,0 \%$ no $4^{\circ}$ relatório, onde foi iniciada a aplicação das estratégias, e novamente, um aumento na dispersão de $10,5 \%$, no $5^{\circ}$ relatório. No período compreendido entre os quatro últimos relatórios, percebeu-se uma tendência mais clara de queda no $\mathrm{CV}$, atingindo o menor valor do semestre na $8^{\circ}$ entrega, com $4,3 \%$ de dispersão.

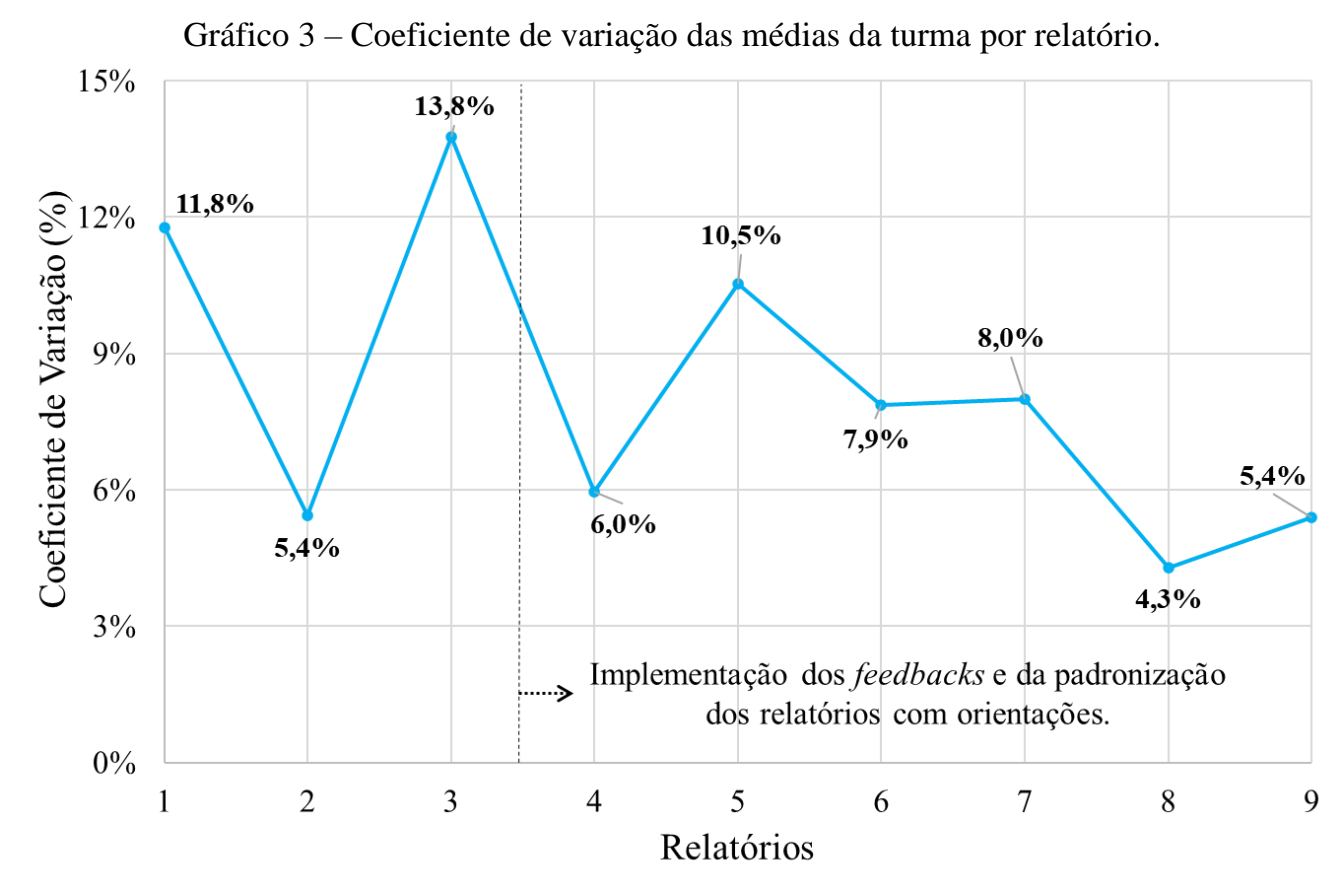

Fonte: Os próprios autores. 
No Gráfico 4, é sumarizado o progresso no desempenho dos alunos a partir da comparação das médias obtidas com os 3 primeiros relatórios, antes da implementação do sistema de feedbacks e do modelo de relatório simplificado, com as médias dos 6 relatórios redigidos após a implementação das estratégias.

Gráfico 4 - Percentual de alunos que aumentaram e que diminuíram seu desempenho nas notas médias dos relatórios na análise antes-depois da implantação das estratégias de feedback e padronização.

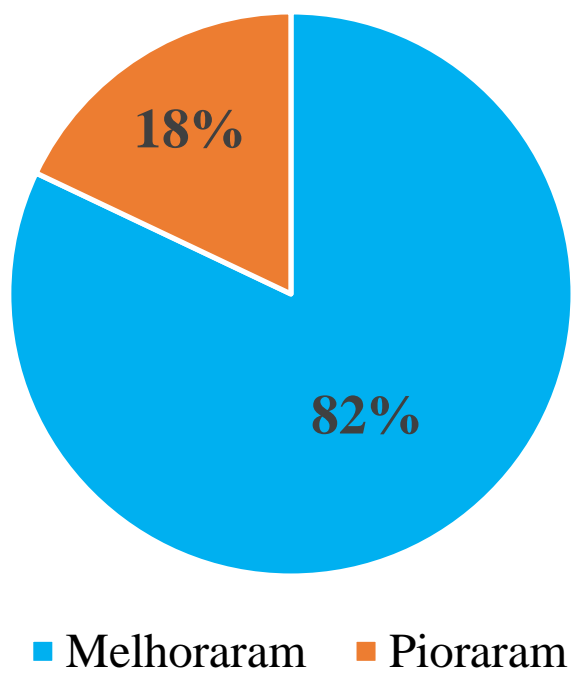

Fonte: Os próprios autores.

Ficou evidente que a ampla maioria dos estudantes, $82 \%$, melhorou seu desempenho médio nos relatórios ao longo do semestre, contra $18 \%$ que tiveram seus resultados diminuídos. Se essa variação fosse aleatória, seria esperada uma distribuição de 50\%/50\% entre os que aumentam e os que diminuem suas notas.

A redução de desempenho desses $18 \%$ (7 alunos) nas notas dos relatórios, pode ser justificada pela ausência de entrega de algum relatório. A partir da análise das notas, foi observado que 4 alunos deixaram de cumprir alguma entrega, provavelmente, por já terem atingido a nota suficiente para aprovação ao final da disciplina. Por outro lado, 3 alunos, embora ainda precisassem de nota, não entregaram relatórios em pelo menos 2 ocasiões nas semanas finais da disciplina, levantando a hipótese da sobrecarga de atividades, característica do fim de semestre.

\section{CONSIDERAÇÕES FINAIS}

Este trabalho apresentou uma avaliação de estratégias de padronização de relatórios e de implementação de um sistema de feedback semanal na parte prática da disciplina de Materiais de Construção Civil I, para alunos de $2^{\circ}$ ano de Engenharia Civil. Em linhas gerais, foi observada eficácia das estratégias adotadas, visto que a maior parte (82\%) dos estudantes tiveram desempenho melhorado na elaboração dos relatórios, e que os alunos inicialmente no quarto quartil de desempenho puderam obter notas médias nos relatórios semelhantes às do primeiro quartil ao fim do semestre. Além disso, aproximou-se a atividade dos relatórios do universo habitual dos laudos de engenharia. Menciona-se ainda que a construção padronizada de textos técnicos por parte dos alunos colabora para o desenvolvimento de habilidades essenciais para a profissão, como objetividade, poder de síntese (concisão), capacidade de 
analisar resultados e a consequente aptidão para tomar decisões. Acredita-se que o direcionamento de esforços em prol da melhoria da aprendizagem e da humanização dos processos pedagógicos pode ajudar a diminuir os números de evasão nos cursos de engenharia e, ainda, aumentar o nível de instrução dos futuros profissionais. Assim, recomenda-se que o mecanismo de feedback seja empregado e avaliado de modo a tornar evidente sua função na evolução do desempenho dos estudantes.

Apesar de os relatórios representarem uma parcela minoritária da nota final da disciplina (10\%), eles têm papel fundamental tanto na formação dos alunos quanto na construção da média final, pois acabam por determinar a aprovação de muitos alunos que atingem desempenhos limítrofes em provas escritas. Um bom desempenho nos relatórios pode ajudar alunos com notas não tão elevadas nas avaliações escritas, usualmente mais complexas e que envolvem fatores incontroláveis (como ansiedade, condições de realização no dia da prova etc.), a conseguirem sua aprovação no final da disciplina.

\section{REFERÊNCIAS}

ALMEIDA, Eustáquio. A Evasão nos cursos de Engenharia e a sua relação com a Matemática: uma análise a partir do COBENGE. 2016. 101 f, Dissertação (Mestrado) Universidade Cruzeiro Do Sul, São Paulo, 2016.

FILATRO, A. Design de feedback e avaliação. São Paulo: Pearson, 2008.

HANNA, Gerald. S.; DETTMER, Peggy. A. Assessment for effective teaching: Using context-adaptive planning. Boston: Allyn \& Bacon. 2004.

MACFARLANE, Bruce. Teaching with Integrity: The Ethics of Higher Education Practice. London: Routledge. 2004.

SANTOS, Adilson P. dos. Comportamento da evasão nos cursos de engenharia da Escola de Minas da Universidade Federal de Ouro Preto. In: Congresso Brasileiro de Ensino de Engenharia, 1998, São Paulo. Anais. São Paulo, 1998.

ZEFERINO, A. M. B.; DOMINGUES, R. C. L.; AMARAL, E. Feedback como estratégia de aprendizado no ensino médico. Revista Brasileira de Educação Médica, Rio de Janeiro, v. 31, n. 2, p. 176-179, 2007.

\section{EFFECT OF THE IMPLEMENTATION OF WEEKLY FEEDBACKS ON THE STUDENT'S REPORTS FROM THE PRACTICAL CLASSES OF CONSTRUCTION MATERIALS}

Abstract: The courses of Construction Materials, from the third and fourth semesters of the civil engineering programme, are the first opportunities for specific contact of students with topics that will be part of their professional experience. Through practical classes in the laboratory, students learn about the process of material characterization tests and their technological control, preparing technical reports for each class. As a result of the students' 
recurring errors in the texts, a weekly feedback routine on the reports was implemented, as well as a standardized model of simplified practical class report. The aim of this paper is to evaluate the benefits of those two actions, performed by the course's mentoring team. In order to evaluate the effectiveness of the measures taken, a statistical analysis was used to compare previous grades with grades obtained after the implementation of the measures. An average grade increase was observed in all quartiles analyzed. A greater increase in the performance of students with lower grades (especially the 4th quartile) was observed prior to the application of the feedback routine, with this evolution being approximately $18 \%$ in the average grade of the reports. The strategy balanced the performance of the students, who had more dispersed grades before the implementation, with a coefficient of variation of $11.8 \%$, reducing to $5.4 \%$ at the end of the semester. Finally, it was found that $82 \%$ of the class had its performance improved after the implementation of the feedbacks system, confirming the effectiveness of the method for the situation analyzed here.

Keywords: Civil Engineering. Weekly feedback. Technical reports. Standardization. 